Motrivivência Ano XXI, No 32/33, P. 401-409 Jun-Dez./2009

\title{
ESPORTE AQUÁTICO: uma visão de lazer e sustentabilidade para o complexo poliesportivo da Ponta Negra
}

\author{
Sandra Maria dos Santos' \\ Maria Cleide Meireles C. Queiroz ${ }^{2}$
}

\begin{abstract}
Resumo Abstract
O Complexo Poliesportivo da Ponta

Negra encontra-se na cidade de Manaus/AM, em frente ao seu mais belo rio, o Negro, foi palco de grande visitação da população manauara utilizado como balneário e hoje se destaca pela prática de esportes, por

possuir grandes empreendimentos de luxo. A carência de uma atividade esportiva na água e a degradação dos demais balneários públicos de Manaus fez o objetivo deste trabalho em mostrar a possibilidade de inserir novas modalidades esportivas amadora no espaço do balneário da Ponta Negra, utilizando a natureza e o esporte como parceiro da sustentabilidade. Utilizou-se a pesquisa descritivo-

The sport Complex of the Ponta Negra meets in the city of Manaus/ Am, in front of its more beautiful river, the Black, was scene of great visitation of the population manauara used as balneal and today it is distinguished for the practical one of sports, for possessing great enterprises of luxury. The lack of the sport activity in the water and the degradation of the excessively balneal public of Manaus made the objective of this work in showing the possibility to insert new sport modalities amateur in the space of the health-resort of the Ponta Negra, using the nature and the sport as partner of the support. It was used description-qualitative
\end{abstract}

1 Turismóloga. Contato: sandra_leoa12@hotmail.com

2 Professora Ed. Física. Universidāde Estadual do Amazonas-UEA. Contato: rickesandra@bol.com.br 
qualitativa como método de pesquisa, 200 formulários de entrevistas, no mês de julho/2005. Concluindo que a população mostrou-se favorável as atividades aqui propostas fazendo o resgate da relação homem-natureza.

Palavras-chave: Balneário da Ponta Negra - esporte Aquático - qualidade de vida - sustentabilidade research as method of research, 200 forms of interviews, in the month of july/2005. Concluding that the population revealed favorable to the activities proposals making here the rescue of the relation man-nature Keywords: Health-resort of the Ponta Negra - Aquatic sport - quality of life - support

\section{Introdução}

Para o sociólogo alemão Max Weber, o trabalho é uma "necessidade vital" do homem e este vem buscando, através dos tempos e das lutas trabalhistas, a continuidade de suas atividades econômicas e, contudo, a diminuição do ritmo de trabalho através do tempo livre.

O lazer não entra para se opor ao trabalho e sim, contribuir para a quebra do cotidiano e da fadiga causada pelo trabalho, visando proporcionar a restauração das forças perdidas após 44 horas de trabalho semanal de esforço físico ou intelectual, assim o lazer entra para o restauro psicológico e físico, desobrigado das questões políticas, religiosas, familiares ou sociais.

Tendo em vista os novos rumos das questões capitalistas e ambientais, o lazer e o turismo vêm se adequando em busca da valorização do natural.

O tempo de lazer dedicado às atividades esportivas é o mais adequado quando se refere às questões sociais, intercambio cultural, mensuração das classes de uma sociedade e minimização dos impactos causados ao ambiente, praticado por uma classe seja ela elitisada ou não, através do espírito competitivo e estratégias para alcançar à vitória, desenvolvendo o lado lúdico-intelectual alcançando a qualidade de vida através do esporte sustentável.

"Esporte aquático: uma visão de lazer e sustentabilidade para o complexo poliesportivo da Ponta Negra" irá mostrar a possibilidade de inserir novas modalidades esportivas amadora no espaço do balneário da Ponta Negra, utilizando a natureza, a água, como grande

3 Trabalho apresentado como comunicação oral no VIII Seminário Nacional de Políticas Públicas Esporte e Lazer -Manaus/Am - Universidade Federal do Amazonas 
Ano XXI, n 32/33, junho e dezembro/2009

parceiro das atividades aqui propostas, com uma visão mais sustentável mediante sua utilização ${ }^{3}$.

A pesquisa descritivoqualitativa utilizou como método de pesquisa, 200 formulários de entrevistas, no mês de julho de 2005, com os freqüentadores de ambos os sexos de 13 a 46 anos, no complexo poliesportivo da Ponta Negra.

Através de uma consciência limpa, os comerciantes, moradores, órgãos públicos e esportistas local poderão integrar-se, na luta do desenvolvimento local sustentável.

\section{Lazer: Turismo e o Esporte Aquatico}

O capitalismo, juntamente coma revolução industrial introduziu, no homem uma nova maneira de utilizar seu tempo. Essa nova sociedade atribuiu ao tempo valor singular, de um lado os processos de produção e de outro uma mãode-obra fadigada pelo excesso de jornadas de trabalho.

O lazer foi uma grande vitória dentro do advento da sociedade industrial. PARKER (1978) afirma que "um aspecto característico das sociedades industriais é que a escassez de alimentos deu lugar à escassez de tempo com implicações especiais para o comportamento diante do lazer". O tempo livre foi associado aos ganhos dos trabaIhadores, à semana de 40 horas, à semana inglesa, às férias e à aposentadoria (Paiva, 1995).

O tempo divide-se em tempo biológico, utilizado para suas necessidades humanas, o tempo de trabalho, como o próprio nome já o diz e por fim o tão desejado tempo livre, que segundo CASTELLI (2001), compreende a parcela de tempo ocupada com atividades específicas, fora do tempo de trabalho, a partir de uma livre decisão. Claro que o tempo livre poderá ser morto, como um pileque, comprometido, de caráter obrigatório como os bicos e o tempo disposto para o lazer.

Então CAMARGO (1992) define lazer como, um conjunto de atividades gratuitas, prazerosas voluntárias e liberatórias, centradas em interesses culturais, físicos, manuais, intelectuais, artísticos e associativos, realizado num tempo livre ou ócio profissional ou doméstico.

As atividades exercidas dentro do tempo de lazer, daqui em diante chamarão de recreação, como CHON (2003), define renovação das forças e do espírito após o trabalho, um meio de diversão. A recreação surgiu de forma natural, instintiva e espontânea através dos folguedos infantis, estendendo-se posteriormente a fase adulta, podendo ser executada em atividades dentro ou fora de casa, este caso nos 
interessa por está relacionado com o esporte e o turismo.

DUMAZEDIER (1999) classifica lazer: físicos, práticos, intelectuais, artísticos e sociais, com espaços oferecidos de acordo com os mesmo. Os profissionais que executam tais atividades são chamados por alguns autores como animador recreacional, militante cultural, liderança recreacional, esses profissionais exercem funções desde a administração do equipamento de lazer e serviços até animando todas as atividades do centro (Dulcio Vaz, 2003; Dumazedier, 1976; Marcelino, 1995).

O tempo turístico está inserido dentro do tempo disposto para o lazer. Com o tempo livre, o homem motivou-se as viagens por lazer, como também para os negócios, peregrinações religiosas, conhecimentos científicos, entre outras (Paiva, 1995). A viagem turística atual é decorrência da sociedade industrial e passou a ser para o homem urbano uma necessidade. O tempo turístico é o tempo de lazer, que pode ser ocupado com múltiplas atividades, porém, consumido fora da residência habitual (Castelli, 2001).

Para TRIBE (2003) turismo é uma visita durante pelo menos uma noite para lazer e férias, finalidades comerciais e profissionais ou outras finalidades de turismo. Visitação significa um movimento temporário para destinos fora da cidade de moradia e de local de trabalho.

Cada vez mais freqüentes as viagens, realizadas por desportistas, torcedores, atletas, tanto em níveis regionais com internacionais, principalmente em mega-eventos. Esses visitantes quando não estão trabalhando estão exercendo atividades de turismo utilizando os equipamentos, compras e outras atividades.

BENI (2001) define o turismo desportivo como deslocamento de turistas aficionados das distintas modalidades de esportes, que afluem a núcleos esportivos tradicionais com calendário fixo de eventos ou de núcleos que eventualmente sediem olimpíadas, competições e torneios. Nesse caso o principal produto turístico é o esporte.

A "moda" muda e com ele surgem novas alternativas de esportes e novas maneiras de praticar os antigos. As propensões dessas atividades surgem tendo como palco, cenário e público, a natureza.

A prática em contato com a natureza fez surgir a "indústria do tempo livre" que se não for bem planejada e gerida de forma correta, o local com tantas belezas cênicas poderão desaparecer.

A partir do artigo "Divertindo na água" de Rojas, o esporte aquático é um meio de educação 
Ano XXI, n 32/33, junho e dezembro/2009

física sumamente importante e rica em seus benefícios, alternativas de nos exercitar sem exigirmos grandes dotes físicos.

É natural, e assim demonstram atividades espontâneas das crianças, em sua grande maioria, manifestam grande atração na prática das atividades aquáticas de maneira informal. Dessa forma a natação destaca-se dentre as opções de esporte aquático, envolvendo atividades lúdicas e especialização esportiva.

As atividades aquáticas poderão ser exercidas com ou sem elementos e de desenvolvimento, desenvolvendo a força, resistência, velocidade e a convivência, etc. Quanto à participação poderá ser ativa, semi-ativa ou passiva, onde a atividade motriz é mínima e se sobressaem à reflexão e a analise.

Normalmente as atividades aquáticas são realizadas em piscinas, mais o intuito é de trazer para um ambiente aberto, buscando a valorização do espaço que se perderão com o uso das novas tecnologias. Essas atividades deverão ser desenvolvidas com a presença do profissional já mencionado e o praticante possuir técnicas de natação.

Podemos citar dentre as atividades das novas inclinações e que desempenharia um ótimo papel no balneário: natação recreacional, hidrocapoeira, tirolesa, acquavolley e o handebol aquático.

\section{Esporte e a Água: questões de Sustentabilidade}

Só no final do século XIX e no principio do século XX, as águas já dessacralizadas pela sociedade industrial, passam a despertar interesse esportivo, recreativo e turístico. Assim, o turismo utiliza seus próprios recursos acaba subtraindo os ecossistemas marinhos e continentais à beleza que estimulou sua ocupação.

Depois de tornar insuportável o atrativo, os pioneiros exploradores do lugar procuram outros para iniciar o mesmo processo. Dentre os principais exemplos no Brasil temos: Ponte da Bolívia e Tarumã, Praia da Barra da Tijuca, de Leblon e Ipanema, Copacabana, Cabo Frio e Búzios, de Guarapari e arredores do Nordeste de modo geral, e outros.

A água por ser um elemento vital ao ser humano, trouxe encanto, fascínio sobre as fontes, rios, lagos e mares, fazendo com que as pessoas às busquem por diversão e repouso.

O turismo balneário é a forma mais procurada nessa era industrial, pois através das diversas formas de relevo das águas, significam liberdade, alívio e naturalidade de vida. Em busca do viver pleno da humanidade, onde nos encontramos a destruição das belezas dos recursos naturais. 
Apesar da utilização generalizada do turismo balneário para a recreação na água, por sua natureza, por seu potencial e suas origens vitais. O Brasil é um dos maiores redentores dos recursos hídricos do mundo, subtiliza seu potencial por falta de conhecimento e informação da população e políticas públicas que visem a melhor exploração da água.

Segundo Pillmann (1992) apud RUSCHMANN (1997), os impactos ambientais causado pelo turismo de esportes na água, citam: natação, esqui, passeio de barco, participação em competições, tem impactos diretamente nos afluentes, poluição do ar e da água, danos a áreas residenciais, agressão á natureza pela construção de equipamentos e ginásio de esporte, vandalismo.

A crise ambiental da atualidade esta levando a construção de um novo paradigma ou uma nova atitude diante da natureza. Praias, rios e lagoas não são apenas bordas do mar ou margens que canalizam os cursos d'água ou que encerram uma porção dela. A água não é deposito de lixo e esgoto, devem ser respeitados seus habitantes como plantas, animais e outros organismos indispensáveis à saúde, então deverá ser considerado sua taxa de esgotamento para sua renovação e conservação para as gerações, ten- do como grande parceiro quanto a controlar o número de praticantes é o preço.

As atividades aqui propostas cabem nesse perfil. Também os próprios consumidores de lazer e turismo têm poder de mudar os efeitos ambientais, comprando somente aqueles que possuem tais responsabilidades.

\section{Complexo Poliesportivo da Ponta Negra}

A Praia da Ponta Negra foi palco de grande visitação da família manauara, nos finais de semana e feriados, usufruindo do esporte e lazer diante de sua natureza exuberante.

O banho refrescante, o jogo de vôlei, futebol, bóia de borracha de câmaras de pneus, proporcionava um relaxamento total.

Depois de um tempo tornou-se esquecida, ocasionado por problemas ambientais e degradação, como: saneamento, limpeza, segurança e poluição. Após sua recuperação voltou com novos equipamentos e a integrar novamente ao cartão portal de Manaus.

Dentre as atividades na água da ponta negra destaca-se: Circuito de água abertas, competição de Remo, Maratona aquática Almirante Tamandaré. 
Ano XXI, n 32/33, junho e dezembro/2009

\section{Resultados}

a) Quanto à motivação, das 200 pessoas entrevistadas 39\% responderam que visitam a Ponta Negra devido ao ambiente, que para eles é o natural, a beleza cênica do local, enquanto $19 \%$ seriam práticas esportivas, $15 \%$ por falta de opção, $13 \%$ a caminhada e $14 \%$ outros motivos do qual o mais relevante é o lazer.

Em cima dos dados percebe-se que o fluxo maior de freqüentadores da Ponta Negra é pela paisagem local. Com isso pode-se confirmar o resultado da pesquisa como verdadeiro trazendo para o espaço Ponta Negra, com ambientes naturais e culturais, destacando o interesse natural.

b) Pontos que poderiam tornar a Ponta Negra mais atraente: Para $42 \%$ dos entrevistados o que poderia melhorar a atratividades da Ponta Negra seria atenção especial à limpeza. Outros 23\% responderam que poderia haver mais eventos destinados à população manauense. $19 \%$ deram ênfase ao esporte aquático, $12 \%$ arborização e $4 \%$ outras opções, destacam-se: segurança, conservação e a retirada ou organização dos bares. Temos o esporte aquático em terceiro lugar, mais se deve levar em consideração, o fato de que a primeira opção falta de limpeza, impossibilitar a realização da atividade.
C) Fatores que mais agradam os visitantes: Quando Ihes foi perguntado sobre o que mais agrada os entrevistados na Ponta Negra, $41 \%$ responderam o Rio Negro, $25 \%$ o calçadão, $16 \%$ as quadra, $12 \%$ os show e os eventos, $3 \%$ bares e lanchonetes e 3\% ambiente em geral. Relacionado com as questões anteriores, percebe-se que o ambiente natural, desponta como atrativo fundamental para os freqüentadores, delimitado neste tópico pelo Rio Negro, por sua extensão e ser exótico. Temos o calçadão com grande relevância, no sentido em que a cidade de Manaus é escassa de ciclovias, espaços próprios para circulação de bicicletas e para caminhadas.

d) O uso da Ponta Negra para atividades de lazer: Nesse item foi perguntado aos visitantes se eles utilizavam a Ponta Negra para alguma prática de esporte. Os resultados apresentaram que $36 \%$ nunca praticaram, mas pretende; $28 \%$ já praticaram ou pratica, por isso afirmam falta de opções; $13 \%$ não praticam, mas já praticou; $13 \%$ praticam. Percebeu-se que uma minoria que praticam alguma atividade esportiva no local, algumas confessam falta de opções, tanto para crianças quanto para adultos. As que não praticam mostraram-se interessadas em participar de uma ou outra atividade ali dispostas. 
e) Divulgação dos esportes aquáticos desenvolvidos: Quando perguntado sobre o conhecimento dos esportes aquáticos praticados na Ponta Negra, 52\% afirmaram que nunca ouviu falar, $21 \%$ sabia sobre a natação e $27 \%$ citaram o remo e menos de $1 \%$ outra atividade. Ao analisar, levando em consideração que a Travessia Almirante Tamandaré já ocorre há 33 anos e que o remo somente iniciou nos idos de 1920, pode-se concluir que o esporte aquático ainda não faz parte da cultura amazonense, apesar da região ser cercada por água.

f) Possibilidade da prática de esporte aquático pelos visitantes: A maioria do entrevistados $71 \%$ responderam que praticariam a atividade e $29 \%$ responderam que não, ou por não saber nadar ou por não gostar da modalidade, sendo assim, pode-se concluir que há certa falta de divulgação e envolvimento nesses esportes, tornado-as mais acessíveis ao público e incluindo atividades das novas tendências aquáticas supracitadas. No entanto deverá haver envolvimento de todos os atores do local buscando atividades cada vez menos poluentes e envolvimento da população para criar nessas a necessidade da conservação desse espaço.

\section{Conclusão}

O tema aqui disposto se originou da carência em utilizar uma das paisagens mais belas de Manaus que é a Ponta Negra, em suma o rio Negro, de forma sustentável, utilizando o fator tempo, requerendo uma consciência pelo fator espaço para o inicio desse projeto.

Diante disso as atividades aqui sugeridas mostraram que é possível maximizar os pontos positivos e minimizar os negativos no que se refere ao lazer na natureza. A proximidade do rio fará um resgate da vivencia da vida antes de Manaus, trazendo a qualidade de vida, a valoração de novos conhecimentos, auto-reflexão, a oportunidade de estreitar as relações com os familiares e de amizade, através de um lazer que não reduz o consumo do bem, que é a água.

\section{REFERENCIAS}

BENI, Mário Carlos. Análise estrutural do turismo. 4 ed. São Paulo: Senac, 2001.

CASTELI, Geraldo. Turismo: atividade marcante. 4 ed. revisada e ampliada - Caxias do Sul: Educs, 2001.

CAMARGO, Luís L.O. O que é lazer. São Paulo: Brasiliense, 1986.

CHON, K.S. Hospitalidade: conceitos e aplicações. São Paulo: Pioneira, Thomson Learning, 2003. 
DULCIO VAZ, Leopoldo Gil. O profissional do turismo e lazer. EF Desportes. Revista Digital. Buenos Aires, Año 9, n. $65,10 / 2003$. Disponível em: http://www.efdesportes.com. br. Acesso em 03 de março de 2005.

DUMAZEDIER, Joffre. Lazer e cultura popular. São Paulo: Perspectiva, 1976.

- Sociologia empírica do lazer. 2 ed. São Paulo: Perspectiva, 1999.

MARCELLINO, Nelson C. Lazer: formação e atuação profissional. Campinas/SP: Papirus, 1995.

ROJAS, Carlos Fierro. La Recreación acuática. EF Desportes. Revista Digital. Buenos Aires. Disponível em http://www.efdep.com.ar/ deportes/la_recreacion_acuatica. htm > acesso em: 03 de março de 2005.

RUSCHMAN, Doris Van de Meene. Turismo e planejamento sustentável: A proteção do meio ambiente. Campinas/SP: Papirus, 1997.

PAIVA, Ma das Graças de Menezes

V. Sociologia do turismo. $8 \mathrm{ed}$. Campinas/SP: Papirus, 1995.

PARKER, Stanley. A sociologia do lazer. Rio de Janeiro: Zahar, 1978.

TIBRE, John. Economia do lazer e do turismo. Trad. de Maria Cláudia Pires Lopes, 2 ed. São Paulo: Manole, 2003.

Recebido: Agosto/2009 Aprovado: Março/2010 